\title{
Multi-Wavelength Pulse Oximeter Is Not Suitable for Adjusting $\mathrm{D}_{\mathrm{LCO}}$ Measurements
}

\author{
Gregg L Ruppel MEd RRT RPFT FAARC, Holly A Wilson RPFT, Vanessa K Gall RRT CPFT, \\ and John A Hempkens BSRT RRT
}

\begin{abstract}
BACKGROUND: Diffusing capacity of the lung for carbon monoxide $\left(\mathrm{D}_{\mathrm{LCO}}\right)$ can be affected by abnormal hemoglobin $(\mathrm{Hb})$ or carboxyhemoglobin $(\mathrm{COHb})$ levels. Predicted $\mathrm{D}_{\mathrm{LCO}}$ can be adjusted to reflect abnormal $\mathrm{Hb}$ or $\mathrm{COHb}$ levels. Until recently, blood sampling was required to determine $\mathrm{Hb}$ and $\mathrm{COHb}$ levels, but a new pulse oximeter, the Masimo RAD-57, can measure $\mathrm{Hb}$ and $\mathrm{COHb}$ noninvasively. We hypothesized that there would be no significant difference between the invasive and noninvasive $\mathrm{Hb}$ and $\mathrm{COHb}$ measurements for adjusting $\mathrm{D}_{\mathrm{LCO}}$. METHODS: In patients referred to our university hospital for $\mathrm{D}_{\mathrm{LCO}}$ testing, we simultaneously took arterial blood gas samples and measured $\mathrm{Hb}$ and $\mathrm{COHb}$ with the RAD-57 ( $\mathrm{SpHb}$ and $\mathrm{SpCOHb}$, respectively). We analyzed the paired values and the $\mathrm{Hb}$-adjusted and $\mathrm{COHb}$-adjusted predicted $\mathrm{D}_{\mathrm{LCO}}$ values with $t$ tests and Bland-Altman plots. We compared the differences in predicted $D_{L C O}$ to a clinical threshold of $3 \mathrm{~mL} / \mathrm{min} / \mathrm{mm}$ Hg. RESULTS: SpHb differed from Hb measured via arterial blood analysis $(12.1 \pm 2.4 \mathrm{~g} / \mathrm{dL}$ vs $13.3 \pm 2.1 \mathrm{~g} / \mathrm{dL}, P<.001)$. SpCOHb did not differ significantly from $\mathrm{COHb}$ (ie, measured via arterial blood analysis) $(2.1 \pm 4.0$ vs $2.5 \pm 2.3, P=.25)$, but there was wide variability. There were small but statistically significant differences in the adjusted predicted $D_{L C O}$, depending on whether blood or pulse oximetry values were used. Predicted $\mathrm{D}_{\mathrm{LCo}}$ adjusted for both $\mathrm{Hb}$ and $\mathrm{COHb}$ was $22.5 \pm 4.8 \mathrm{~mL} / \mathrm{min} / \mathrm{mm} \mathrm{Hg}$ measured with the RAD-57 and $23.5 \pm 4.5 \mathrm{~mL} /$ $\mathrm{min} / \mathrm{mm} \mathrm{Hg}$ via arterial blood analysis $(P<.001)$. The limits of agreement for pulse oximetry adjusted $D_{L C O}$ exceeded the clinical threshold of $3 \mathrm{~mL} / \mathrm{min} / \mathrm{mm} \mathrm{Hg}$ for $\mathrm{Hb}$ adjustments and combined $\mathrm{Hb}+\mathrm{COHb}$. Predicted $\mathrm{D}_{\mathrm{LCO}}$ values differed by $>3 \mathrm{~mL} / \mathrm{min} / \mathrm{mm} \mathrm{Hg}$ in $17 \%$ of patients. CONCLUSIONS: Pulse oximetry may be of limited usefulness for adjusting either predicted or measured $D_{\mathrm{LCO}}$ values, but might be useful to screen patients for invasive testing, particularly if the $\mathbf{D}_{\mathbf{L C O}}$ is close to the lower limit of normal. Key words: diffusing capacity; pulse oximetry; arterial blood analysis; hemoglobin; carboxyhemoglobin; predicted values; lung function tests. [Respir Care 2011; 56(8):1115-1121. ㅇ 2011 Daedalus Enterprises]
\end{abstract}

\section{Introduction}

Diffusing capacity of the lung for carbon monoxide $\left(\mathrm{D}_{\mathrm{LCO}}\right)$ can be affected by the patient's hemoglobin $(\mathrm{Hb})$ concentration and by back-pressure from carbon monoxide in the blood and an "anemia" effect of $\mathrm{CO}$ bound to $\mathrm{Hb}$ (carboxyhemoglobin $[\mathrm{COHb}]$ ) at the time of testing. ${ }^{1}$ The

\footnotetext{
Mr Ruppel, Ms Wilson, and Ms Gall are affiliated with the Pulmonary Function Laboratory, Pulmonary, Critical Care, and Sleep Medicine Department; and Mr Hempkens is affiliated with the Respiratory Care Department, St Louis University Hospital, St Louis, Missouri.
}

The authors have disclosed no conflicts of interest.
American Thoracic Society/European Respiratory Society guidelines for $\mathrm{D}_{\mathrm{LCO}}$ testing with the single-breath method recommend adjusting all reported $\mathrm{D}_{\mathrm{LCO}}$ for the effects of $\mathrm{Hb}$ and $\mathrm{COHb}$, for interpreting the results. ${ }^{2}$ Earlier guidelines suggested adjusting the measured $\mathrm{D}_{\mathrm{LCO}}$ with the equations of Cotes et $\mathrm{al}^{3}$ for $\mathrm{Hb}$ and an empirical equation that

\footnotetext{
Correspondence: Gregg L Ruppel MEd RRT RPFT FAARC, Pulmonary Function Laboratory, Pulmonary, Critical Care, and Sleep Medicine Department, Saint Louis University Hospital, 3635 Vista Avenue, St Louis MO 63110-0250. E-mail: ruppelg1@slu.edu.
}

DOI: $10.4187 /$ respcare. 01142 
increases $\mathrm{D}_{\mathrm{LCO}}$ in proportion to the elevation of $\mathrm{COHb}$ above $2 \% .^{2}$ The 2005 guidelines suggest adjusting the predicted $\mathrm{D}_{\mathrm{LCO}}$ as a more appropriate method to gauge the effects of abnormal $\mathrm{Hb}$ or $\mathrm{COHb}$ levels on diffusing capacity. These adjustments, whether applied to the measured or predicted $\mathrm{D}_{\mathrm{LCO}}$, require an accurate $\mathrm{Hb}$ and $\mathrm{COHb}$ measurement from arterial or venous blood obtained near the time of $\mathrm{D}_{\mathrm{LCO}}$ testing.

A new multi-wavelength pulse oximeter, the RAD-57 (Masimo, Irvine, California) can noninvasively measure total $\mathrm{Hb}(\mathrm{SpHb})$ and carboxyhemoglobin $(\mathrm{SpCOHb})$. We investigated the use of $\mathrm{SpHb}$ and $\mathrm{SpCOHb}$ for adjusting $\mathrm{D}_{\mathrm{LCO}}$, which could obviate drawing blood and the associated risks and discomfort. We hypothesized that there would be no significant differences between the $\mathrm{Hb}$ and $\mathrm{COHb}$ values from the RAD-57 and from arterial blood analysis.

\section{Methods}

This study was approved by the institutional review board of St Louis University.

\section{Patients}

We enrolled consecutive patients referred to our university hospital pulmonary function laboratory for pulmonary function studies with $\mathrm{D}_{\mathrm{LCO}}$ and arterial blood gas measurement. All subjects gave informed consent. We recorded age, height, and sex, and used the equations of Gaensler and Wright to calculate predicted $\mathrm{D}_{\mathrm{LCO}}{ }^{4}$

\section{Arterial Blood Sampling and Analysis}

Blood samples were obtained via radial artery puncture, with the patient seated in a blood drawing chair. Each blood specimen was analyzed within 5 minutes (RapidPoint 405, Siemens Healthcare Diagnostics, Deerfield, Illinois). The blood gas analyzer was monitored daily with 3 control levels, which included oximetry values. We report total $\mathrm{Hb}$ in $\mathrm{g} / \mathrm{dL}$, and $\mathrm{COHb}$ as a percentage of $\mathrm{Hb}$.

\section{Pulse Oximetry}

Pulse oximetry measurements were made with the Masimo RAD-57. We purchased 18 new RAD-57s for clinical use in our center, and randomly selected 3 of them for this study. Because separate sensors are required for measurement of $\mathrm{SpHb}$ and $\mathrm{SpCOHb}$, we used $2 \mathrm{RAD}-57 \mathrm{~s}$ simultaneously: one with an $\mathrm{Hb}$ sensor, and one with a $\mathrm{COHb}$ sensor. The third RAD-57 was kept as a back-up, and the 3 RAD-57s were used interchangeably. The sensors were applied to 2 fingers of the opposite hand from which the blood sample was obtained. The oximetry readings were allowed to stabilize, and $\mathrm{SpHb}$ and $\mathrm{SpCOHb}$ were recorded at the time the arterial sample was obtained. The RAD-57 reports $\mathrm{SpCOHb}$ as an integer percentage. We observed for and recorded pulse oximeter warnings, failure to display data, and patient conditions (eg, nail polish) that might compromise the oximetry measurements.

\section{$D_{\text {LCO }}$ Adjustments}

Each patient's predicted $\mathrm{D}_{\mathrm{LCO}}$ was adjusted with the following equations:

Hemoglobin:

Male: Adjusted predicted $\mathrm{D}_{\mathrm{LCO}}=$ Predicted $\mathrm{D}_{\mathrm{LCO}} \times$ $(1.7 \mathrm{Hb} /(10.22+\mathrm{Hb}))$

Female: Adjusted predicted $\mathrm{D}_{\mathrm{LCO}}=$ Predicted $\mathrm{D}_{\mathrm{LCO}} \times$ $(1.7 \mathrm{Hb} /(9.38+\mathrm{Hb}))$

Carboxyhemoglobin:

Adjusted predicted $\mathrm{D}_{\mathrm{LCO}}=$ Predicted $\mathrm{D}_{\mathrm{LCO}} \times(102 \%-$ $\mathrm{COHb} \%$ )

\section{Data Analysis}

We compared the $\mathrm{Hb}$ and $\mathrm{COHb}$ values to the $\mathrm{SpHb}$ and $\mathrm{SpCOHb}$ values with paired $t$ tests and Bland-Altman difference plots.5,6 Bias was defined as the mean difference between the measurements, and error (precision) was defined as the standard deviation of the differences. We defined the limits of agreement between the measurement methods as $\pm 1.96 \mathrm{SD}$ around the mean difference. $P$ values $<.05$ were considered significant. We also used BlandAltman plots to compare the predicted $\mathrm{D}_{\mathrm{LCO}}$ values adjusted with arterial blood analysis ( $\mathrm{Hb}$ and $\mathrm{COHb}$ ) to the $\mathrm{D}_{\mathrm{LCO}}$ values adjusted with the RAD-57 values $(\mathrm{SpHb}$ and $\mathrm{SpCOHb}$ ). If a pulmonary function technologist comment suggested questionable data (eg, low perfusion alarm, no result displayed), the result was considered an outlier and not included in the data analysis. We considered it a clinically important difference if the difference between the arterial-blood adjusted and pulse-oximetry adjusted predicted values was $>3 \mathrm{~mL} / \mathrm{min} / \mathrm{mm} \mathrm{Hg}$.

\section{Results}

Table 1 describes the 149 subjects. Data from 10 subjects were excluded as outliers because of pulse oximeter warnings, or failure of the pulse oximeter to stabilize and display data. Table 2 shows the total $\mathrm{Hb}, \mathrm{COHb}$, and adjusted predicted $\mathrm{D}_{\mathrm{LCO}}$ values. There was a small but significant (via paired $t$ test) difference between $\mathrm{Hb}$ and $\mathrm{SpHb}$. The difference between $\mathrm{COHb}$ and $\mathrm{SpCOHb}$ was not significant because of the wide variability of the measurements. Figures 1 and 2 show the scatter of values for $\mathrm{Hb}$ and $\mathrm{SpHb}$, and $\mathrm{COHb}$ and $\mathrm{SpCOHb}$, respectively. When 
Table 1. Subjects

\begin{tabular}{lc}
\hline \hline Patients, no. & $139 *$ \\
Age $(\mathrm{y})$ & $56 \pm 11$ \\
Male $(\%)$ & 64 \\
White $(\%)$ & 76 \\
Unadjusted predicted $\mathrm{D}_{\mathrm{LCO}}(\mathrm{mL} \mathrm{CO} / \mathrm{min} / \mathrm{mm} \mathrm{Hg})$ & $24.3 \pm 4.4$ \\
& \\
\hline values are mean \pm SD. & \\
* Ten patients were excluded because of pulse oximeter warning or failure to display data. \\
$\mathrm{D}_{\mathrm{LCO}}=$ diffusing capacity of the lung for carbon monoxide \\
\hline
\end{tabular}

Table 2. Hemoglobin, Carboxyhemoglobin, and Adjusted Predicted $\mathrm{D}_{\mathrm{LCO}}$ Values

\begin{tabular}{|c|c|c|c|}
\hline & $\begin{array}{c}\text { Arterial } \\
\text { Blood } \\
\text { Analysis } \\
\text { (mean } \pm \mathrm{SD} \text { ) }\end{array}$ & $\begin{array}{c}\text { RAD-57 } \\
\text { Measurement } \\
\text { (mean } \pm \mathrm{SD})\end{array}$ & $P^{*}$ \\
\hline Total Hb (g/dL) & $13.4 \pm 2.1$ & $12.1 \pm 2.4$ & $<.001$ \\
\hline $\mathrm{COHb}(\%)$ & $2.5 \pm 2.3$ & $2.1 \pm 4.0$ & .25 \\
\hline \multicolumn{4}{|l|}{$\begin{array}{l}\text { Predicted } \mathrm{D}_{\mathrm{LCO}} \\
(\mathrm{mL} / \mathrm{min} / \mathrm{mm} \mathrm{Hg})\end{array}$} \\
\hline $\mathrm{Hb}$ adjusted & $23.6 \pm 4.6$ & $22.5 \pm 4.6$ & $<.001$ \\
\hline $\mathrm{COHb}$ adjusted & $24.2 \pm 4.4$ & $24.3 \pm 4.7$ & .07 \\
\hline $\mathrm{Hb}+\mathrm{COHb}$ adjusted & $23.5 \pm 4.5$ & $22.5 \pm 4.8$ & $<.001$ \\
\hline \multicolumn{4}{|c|}{$\begin{array}{l}\text { *Via 2-tailed paired } t \text {-test. } \\
\mathrm{D}_{\mathrm{LCO}}=\text { diffusing capacity of the lung for carbon monoxide } \\
\mathrm{Hb}=\text { hemoglobin } \\
\mathrm{COHb}=\text { carboxyhemoglobin }\end{array}$} \\
\hline
\end{tabular}

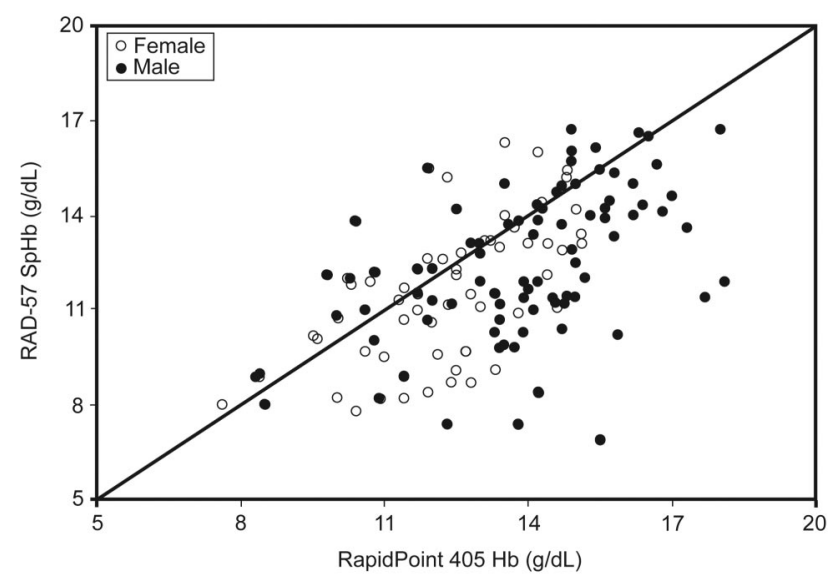

Fig. 1. Scatter plot of hemoglobin $(\mathrm{Hb})$ measured with the RapidPoint 405 blood analyzer versus the RAD-57 pulse oximeter ( $\mathrm{SpHb}$ ). The solid line is the line of identity.

the predicted $\mathrm{D}_{\mathrm{LCO}}$ was adjusted with the 2 methods, there were small but significant differences for the $\mathrm{Hb}$ and combined $\mathrm{Hb}+\mathrm{COHb}$ adjusted values (see Table 2).

Table 3 shows the bias, error (precision), and limits of agreement for the $\mathrm{Hb}, \mathrm{COHb}$, and adjusted predicted $\mathrm{D}_{\mathrm{LCO}}$ values. There was a slight negative bias for both $\mathrm{Hb}$ and

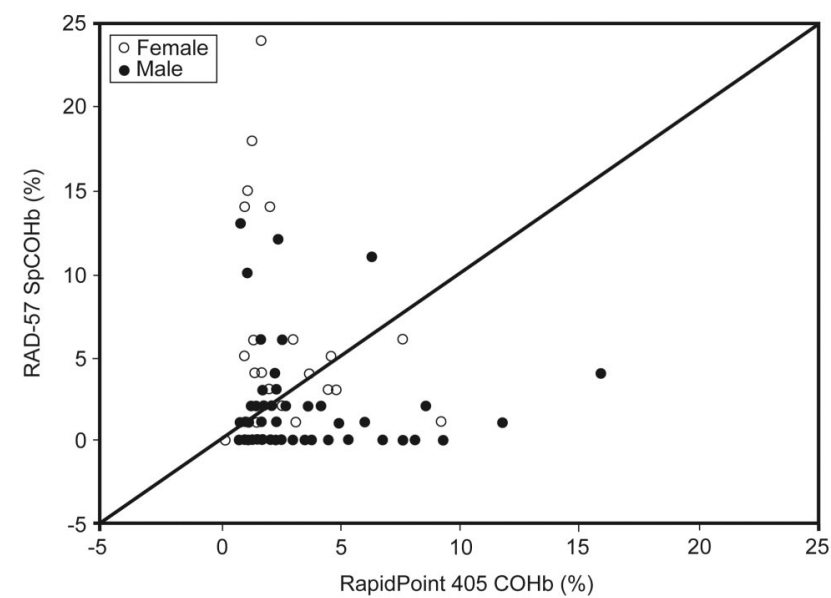

Fig. 2. Scatter plot of carboxyhemoglobin $(\mathrm{COHb})$ measured with the RapidPoint 405 blood analyzer versus the RAD-57 pulse oximeter $(\mathrm{SpCOHb})$. The solid line is the line of identity.

Table 3. Bias, Error, and Limits of Agreement

\begin{tabular}{|c|c|c|c|}
\hline & Bias & Error & $\begin{array}{l}\text { Limits of } \\
\text { Agreement }\end{array}$ \\
\hline $\mathrm{Hb}$ vs $\mathrm{SpHb}(\mathrm{g} / \mathrm{dL})$ & -1.26 & 2.15 & 2.95 to -5.48 \\
\hline $\mathrm{COHb}$ vs $\mathrm{SpCOHb}(\%)$ & -0.39 & 3.98 & 7.41 to -8.20 \\
\hline \multicolumn{4}{|l|}{$\begin{array}{l}\text { Predicted } \mathrm{D}_{\mathrm{LCO}} \\
\quad(\mathrm{mL} / \mathrm{min} / \mathrm{mm} \mathrm{Hg})\end{array}$} \\
\hline $\mathrm{Hb}$ adjusted & -1.11 & 2.01 & 2.82 to -5.04 \\
\hline $\mathrm{COHb}$ adjusted & 0.14 & 0.88 & 1.86 to -1.58 \\
\hline $\mathrm{Hb}+\mathrm{COHb}$ adjusted & -0.95 & 2.20 & 3.37 to -5.26 \\
\hline \multicolumn{4}{|c|}{$\begin{array}{l}\mathrm{Hb}=\text { hemoglobin } \\
\mathrm{D}_{\mathrm{LCO}}=\text { diffusing capacity of the lung for carbon monoxide } \\
\mathrm{SpHb}=\text { hemoglobin measured with the Masimo RAD-57 oximeter } \\
\mathrm{COHb}=\text { carboxyhemoglobin } \\
\mathrm{SpCOHb}=\text { carboxyhemoglobin measured with the Masimo RAD-57 oximeter }\end{array}$} \\
\hline
\end{tabular}

$\mathrm{COHb}$ (arterial blood analysis $>$ pulse oximetry). Figures 3 and 4 show the Bland-Altman plots of the differences between the RAD-57 and RapidPoint 405 measurements versus the averages of the 2 instruments. Figures 5, 6 , and 7 show the bias and limits of agreement between the 2 methods when $\mathrm{D}_{\mathrm{LCO}}$ was adjusted for $\mathrm{Hb}, \mathrm{COHb}$, and $\mathrm{Hb}+\mathrm{COHb}$. The shaded areas in Figures 5, 6, and 7 represent the clinical threshold of $3 \mathrm{~mL} / \mathrm{min} / \mathrm{mm} \mathrm{Hg}$ centered around a difference of zero. For $\mathrm{Hb}$ adjustments the upper limit of agreement was within the clinical threshold, but the lower limit exceeded the threshold by approximately $2 \mathrm{~mL} / \mathrm{min} / \mathrm{mm} \mathrm{Hg}$. The results were similar for the combined $\mathrm{Hb}+\mathrm{COHb}$ adjustments. The limits of agreement were well within the $\pm 3 \mathrm{~mL} / \mathrm{min} / \mathrm{mm} \mathrm{Hg}$ threshold when the predicted $\mathrm{D}_{\mathrm{LCO}}$ was adjusted only for $\mathrm{COHb}$.

Of the 139 patients, $23(17 \%)$ had adjusted $\mathrm{D}_{\mathrm{LCO}}$ values that differed by $>3 \mathrm{~mL} / \mathrm{min} / \mathrm{mm} \mathrm{Hg}$ when the RAD-57 


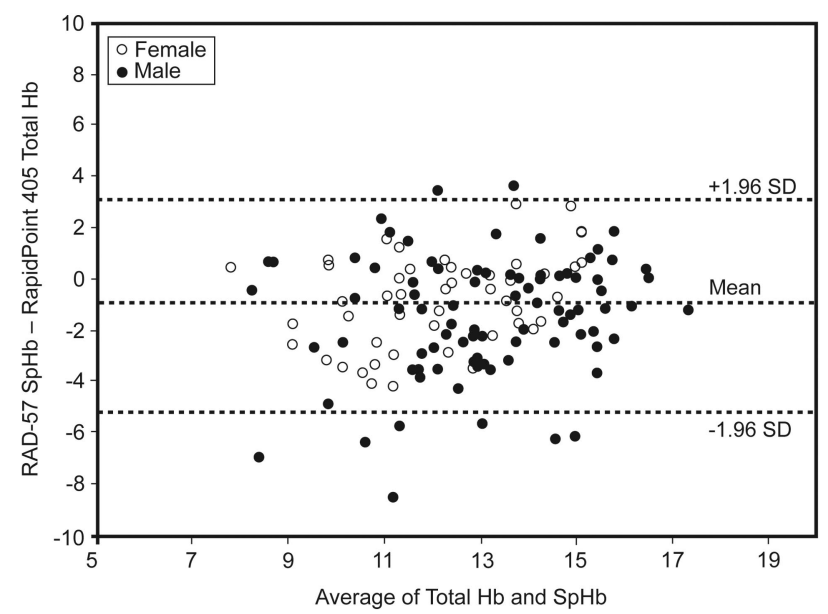

Fig. 3. Bland-Altman plots of hemoglobin $(\mathrm{Hb})$ measured with the RapidPoint 405 blood analyzer versus the RAD-57 pulse oximeter $(\mathrm{SpHb})$. The dashed lines represent the mean and limits of agreement ( $\pm 1.96 \mathrm{SD})$.

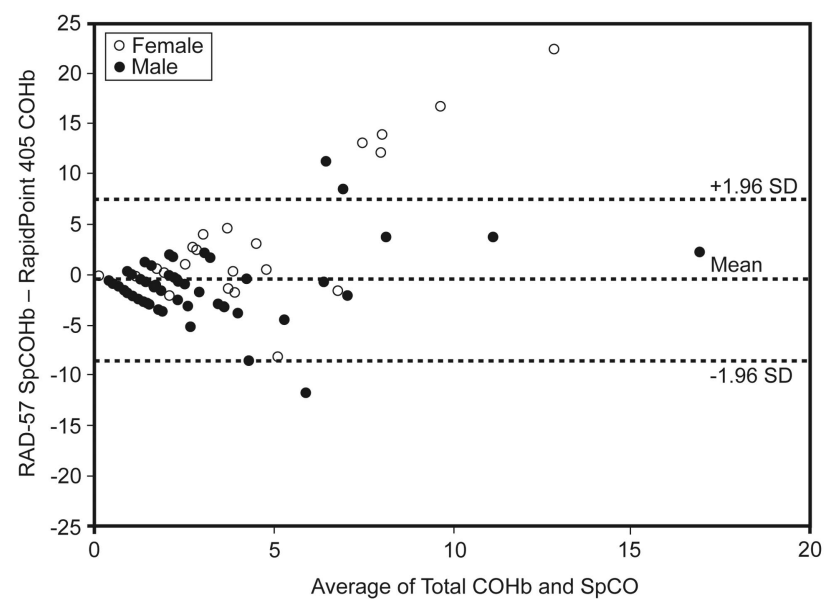

Fig. 4. Bland-Altman plots of carboxyhemoglobin $(\mathrm{COHb})$ measured with the RapidPoint 405 blood analyzer versus the RAD-57 pulse oximeter $(\mathrm{SpCOHb})$. The dashed lines represent the mean and limits of agreement $( \pm 1.96 \mathrm{SD})$. The RAD-57 reports $\mathrm{SpCOHb}$ values as integer percentages, which fall along straight lines when plotted against the $\mathrm{COHb}$ values, which are reported to one decimal place.

value was used (Table 4). Of these, 19 (14\%) differed because of $\mathrm{Hb}$, and 4 (3\%) differed because of $\mathrm{COHb}$.

\section{Discussion}

There was a small but statistically significant difference when the predicted $\mathrm{D}_{\mathrm{LCO}}$ was adjusted with the RAD-57 values, compared to the arterial blood analysis values. For the $\mathrm{Hb}$ measurements there was a small negative bias (arterial blood analysis $>$ pulse oximetry) in addition to significant error, expressed as the SD of the differences. There

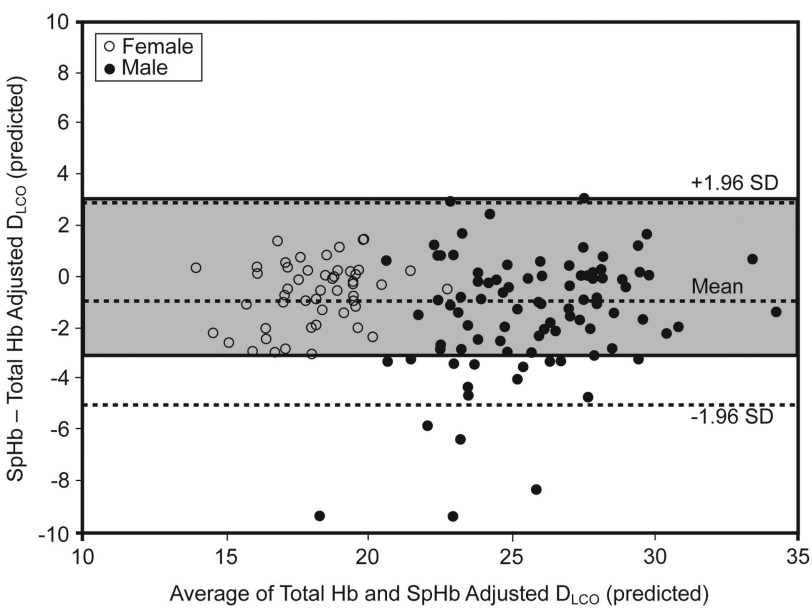

Fig. 5. Bland-Altman plot of diffusing capacity of the lung for carbon monoxide $\left(D_{L C O}\right)$ adjusted with hemoglobin $(\mathrm{Hb})$ values from the RapidPoint 405 blood analyzer versus the RAD-57 pulse oximeter $(\mathrm{SpHb})$. The dashed lines represent the mean and limits of agreement $( \pm 1.96 \mathrm{SD})$. The shaded area represents our defined threshold of clinical importance $( \pm 3 \mathrm{~mL} / \mathrm{min} / \mathrm{mm} \mathrm{Hg}$ ).

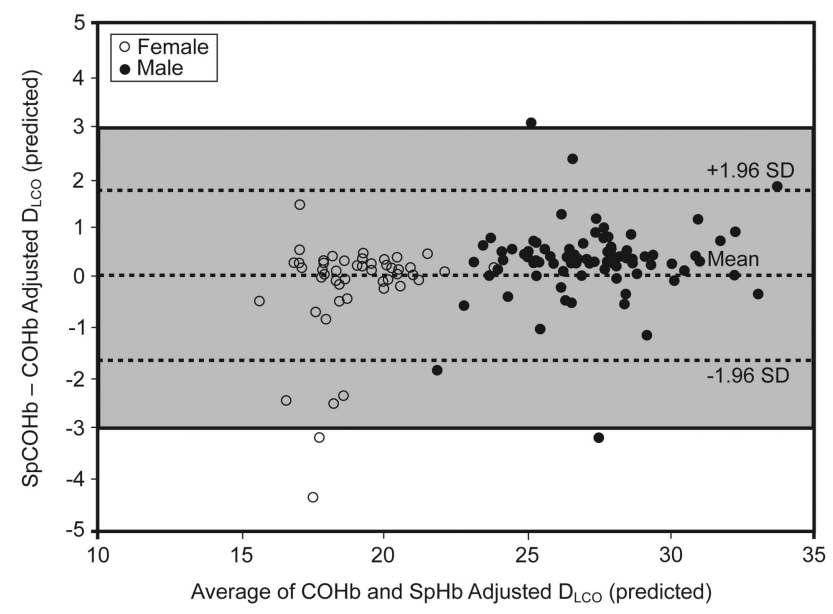

Fig. 6. Bland-Altman plot of diffusing capacity of the lung for carbon monoxide $\left(\mathrm{D}_{\mathrm{LCO}}\right)$ adjusted with carboxyhemoglobin $(\mathrm{COHb})$ values from the RapidPoint 405 blood analyzer versus the RAD-57 pulse oximeter $(\mathrm{SpCOHb})$. The dashed lines represent the mean and limits of agreement ( $\pm 1.96 \mathrm{SD}$ ). The shaded area represents our defined threshold of clinical importance $( \pm 3 \mathrm{~mL} / \mathrm{min} / \mathrm{mm} \mathrm{Hg}$ ).

was poor correlation between $\mathrm{Hb}$ measured by the RAD-57 versus via arterial blood analysis (see Fig. 1). The $\mathrm{COHb}$ and $\mathrm{SpCOHb}$ measurements were not statistically different, but there was wide variability (see Fig. 2).

When the $\mathrm{Hb}$ and $\mathrm{SpHb}$ measurements were used to adjust the predicted $\mathrm{D}_{\mathrm{LCO}}$, the RAD-57 underestimated the adjusted value by approximately $1 \mathrm{~mL} / \mathrm{min} / \mathrm{mm} \mathrm{Hg}$. The limits of agreement between the 2 methods, however, were approximately $4 \mathrm{~mL} / \mathrm{min} / \mathrm{mm} \mathrm{Hg}$, which is slightly greater than the clinical threshold of $3 \mathrm{~mL} / \mathrm{min} / \mathrm{mm} \mathrm{Hg}$, based on the acceptable within-session variability for $\mathrm{D}_{\mathrm{LCO}}{ }^{2} \mathrm{Ad}-$ 


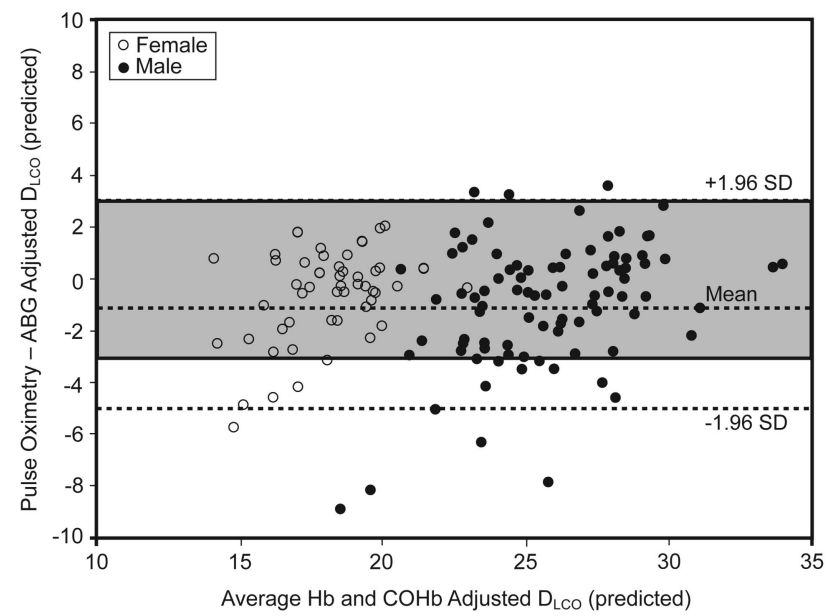

Fig. 7. Bland-Altman plot of diffusing capacity of the lung for carbon monoxide $\left(\mathrm{D}_{\mathrm{LCO}}\right)$ adjusted with both hemoglobin $(\mathrm{Hb})$ and $(\mathrm{COHb})$. The dashed lines represent the mean and limits of agreement $( \pm 1.96 \mathrm{SD})$. The shaded area represents our defined threshold of clinical importance $( \pm 3 \mathrm{~mL} / \mathrm{min} / \mathrm{mm} \mathrm{Hg})$.

Table 4. Subjects in Whom Adjusted Predicted $\mathrm{D}_{\mathrm{LCO}}$ Differed by $>3 \mathrm{~mL} / \mathrm{min} / \mathrm{mm} \mathrm{Hg}(n=139)$

\begin{tabular}{lcc}
\hline \hline $\mathrm{D}_{\mathrm{LCO}}$ Adjusted With & No. & Percent \\
\hline $\mathrm{Hb}$ & 19 & 14 \\
$\mathrm{COHb}$ & 4 & 3 \\
$\mathrm{Hb}+\mathrm{COHb}$ & 23 & 17
\end{tabular}

$\mathrm{D}_{\mathrm{LCO}}=$ diffusing capacity of the lung for carbon monoxide

$\mathrm{Hb}=$ hemoglobin

$\mathrm{COHb}=$ carboxyhemoglobin

justments to predicted $\mathrm{D}_{\mathrm{LCO}}$ based on the $\mathrm{COHb}$ measurements were similar despite some large differences between individual samples. This is partly explained by the equation used for $\mathrm{COHb}$ adjustment (see the Methods section). The limits of agreement for adjusting the predicted $\mathrm{D}_{\mathrm{LCO}}$ for $\mathrm{COHb}$ were approximately one half of the clinical threshold of $3 \mathrm{~mL} / \mathrm{min} / \mathrm{mm} \mathrm{Hg}$.

When predicted $\mathrm{D}_{\mathrm{LCO}}$ was adjusted for both $\mathrm{Hb}$ and $\mathrm{COHb}$, there was a negative bias (arterial blood analysis $>$ pulse oximetry) and the limits of agreement were approximately $4 \mathrm{~mL} / \mathrm{min} / \mathrm{mm} \mathrm{Hg}$, due primarily to the $\mathrm{Hb}$ differences. This suggests that the noninvasive measurement may not be a suitable alternative for adjusting $\mathrm{D}_{\mathrm{LCO}}$, if a threshold of $3 \mathrm{~mL} / \mathrm{min} / \mathrm{mm} \mathrm{Hg}$ is considered clinically important. Some statisticians suggest that the limits of agreement should be $\leq 0.5$ times the coefficient of variation. ${ }^{7}$ Of the 139 subjects, $23(17 \%)$ had a difference $>3 \mathrm{~mL} / \mathrm{min} / \mathrm{mm} \mathrm{Hg}$ between their predicted $\mathrm{D}_{\mathrm{LCO}}$ values. These results suggest that our null hypothesis should be rejected.
Jou et $\mathrm{al}^{8}$ reported (in abstract) a mean \pm SD bias of $0.18 \pm 1.10 \mathrm{~g} / \mathrm{dL}$ in a comparison of the RAD-57 and the i-STAT handheld blood gas analyzer. Lamhaut et $\mathrm{al}^{9}$ reported (in abstract) a mean \pm SD bias of $0.26 \pm 1.11 \mathrm{~g} / \mathrm{dL}$ in a comparison of the RAD-57 and an unnamed laboratory blood gas analyzer. Torp et $\mathrm{al}^{10}$ reported (in abstract) a mean \pm SD bias of $0.2 \pm 0.8 \mathrm{~g} / \mathrm{dL}$ in a comparison of the RAD-57 and a laboratory blood gas analyzer that incorporates oximetry (Nova Biomedical). Each of those investigations considered the utility of trend versus intermittent monitoring as well as the accuracy and precision of the device.

Chung and co-workers ${ }^{11}$ compared the RAD-57 to a laboratory spectrophotometer and found a correlation coefficient of 0.814 for 217 paired samples, but they did not calculate the bias or precision (error), as is usually recommended for method comparisons. Allard et al ${ }^{12}$ reported (in abstract) the results of 335 paired samples in subjects whose $\mathrm{Hb}$ levels were experimentally reduced with phlebotomy. They found a bias of $-0.15 \mathrm{~g} / \mathrm{dL}$ (pulse oximeter vs laboratory analysis) and an error of $0.92 \mathrm{~g} / \mathrm{dL}$. Our results in the present study show a higher bias and error, perhaps related to the comparative method we used (ie, the RapidPoint 405).

Carbon monoxide poisoning is the most common type of fatal poisoning in the United States, with an estimated 500 unintentional deaths and 15,000 emergency department visits annually. ${ }^{13}$ Not all hospitals in the United States have the ability to measure $\mathrm{COHb}$ via arterial blood analysis. Several authors have reported the utility of monitoring $\mathrm{CO}$ via pulse oximetry in the emergency department. Piatkowski et al ${ }^{14}$ reported a mean error of $3.15 \%$ in patients who had $\mathrm{CO}$ poisoning when the pulse oximeter was compared to arterial blood analysis. In their patients whose $\mathrm{COHb}$ was $>10 \%$, the bias and error (precision) were $3.4 \%$ and $2.4 \%$, respectively. That error was only slightly greater than when different blood gas analyzers were compared. Coulange et $\mathrm{al}^{15}$ reported a bias of $1.5 \%$ for $\mathrm{COHb}$ (pulse oximeter $>$ arterial blood analysis) in a cohort of emergency department patients with suspected $\mathrm{CO}$ poisoning. Barker et al studied induced carboxyhemoglobinemia in a small group of healthy volunteers and found a bias of $-1.22 \%$ and a precision of $2.19 \%$ with the RAD-57. ${ }^{16}$ In a letter to the editor, $\mathrm{O}^{\prime}$ Malley ${ }^{17}$ reported a high rate of false positive findings (pulse oximetry $>$ arterial blood analysis), and terminated a prospective study because of the inconsistencies. The present study found a somewhat smaller bias $(0.50 \%)$, but with an error of $3.43 \%$. However, the manufacturer's specifications for accuracy are $\pm 3 \%$ for $\mathrm{COHb}$ levels from $1 \%$ to $40 \%$.

When considering whether one method can be substituted for another, both the bias and error (precision) must be considered. If the bias is constant (ie, does not change with the magnitude of the measurement), it may be cor- 


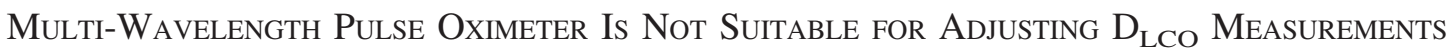

Table 5. Example of Adjusting Measured Versus Predicted $\mathrm{D}_{\mathrm{LCO}}$ *

\begin{tabular}{lccc}
\hline \hline & Measured & Predicted & \% Predicted \\
\hline Unadjusted $\mathrm{D}_{\mathrm{LCO}}{ }^{\dagger}$ & 21.0 & 30.0 & 70 \\
Measured $\mathrm{D}_{\mathrm{LCO}}$ adjusted & 23.3 & 30.0 & 78 \\
Predicted $\mathrm{D}_{\mathrm{LCO}}$ adjusted & 21.0 & 27.0 & 78 \\
Difference & 2.3 & 3.0 & 8
\end{tabular}

* In a male patient with a hemoglobin $(\mathrm{Hb})$ of $11.5 \mathrm{~g} / \mathrm{dL}$.

$\dagger \mathrm{D}_{\mathrm{LCO}}=$ diffusing capacity of the lung for carbon monoxide, reported in $\mathrm{mL} / \mathrm{min} / \mathrm{mm} \mathrm{Hg}$.

rected by addition or subtraction. Of somewhat greater importance is whether the limits of agreement $(1.96 \times \mathrm{SD}$ of the differences) exceed a clinically acceptable threshold. We defined the threshold as $3 \mathrm{~mL} / \mathrm{min} / \mathrm{mm} \mathrm{Hg}$, and deemed that reasonable because it is also the within-session limit of variability for $\mathrm{D}_{\mathrm{LCO}}$ measurements. Any factor (such as $\mathrm{Hb}$ or $\mathrm{COHb}$ adjustment) that might change the predicted value by $>3 \mathrm{~mL} / \mathrm{min} / \mathrm{mm} \mathrm{Hg}$ could be considered clinically important. Changes of this magnitude would be of greatest concern when the patient's $\mathrm{D}_{\mathrm{LCO}}$ is near the lower limit of normal and hemoglobinopathies need to be ruled out.

Applying $\mathrm{Hb}$ or $\mathrm{COHb}$ adjustment factors to a patient's measured $\mathrm{D}_{\mathrm{LCO}}$ produces the same result when expressing the variable as a percent of predicted. Table 5 shows an example, in which the patient has an unadjusted $\mathrm{D}_{\mathrm{LCO}}$ of $70 \%$ of predicted. In this example the patient is a moderately anemic male ( $\mathrm{Hb} 11.5 \mathrm{~g} / \mathrm{dL}$ ), so an adjustment factor of 0.90 might be used, as a multiplier to adjust the predicted value, or as a divisor to adjust the measured value. In either case the patient's percent-of-predicted $\mathrm{D}_{\mathrm{LCO}}$ becomes $78 \%$. However, in terms of an absolute change, the measured value changed by $<3 \mathrm{~mL} / \mathrm{min} / \mathrm{mm} \mathrm{Hg}$. We derived the limits of agreement from adjustments applied to the predicted value as a more conservative comparison to the fixed clinical threshold of $3 \mathrm{~mL} / \mathrm{min} / \mathrm{mm} \mathrm{Hg}$.

\section{Limitations}

The RAD-57 SpHb sensor requires several minutes to stabilize and produce a reading. In some instances, the pulse oximeter reading was changing as the arterial blood sample was being obtained. It is possible that a longer stabilization period might have given a different bias and error. The $\mathrm{SpCOHb}$ sensor stabilized much more quickly. We used several different sensors and 3 RAD-57s (one for $\mathrm{SpHb}$, one for $\mathrm{SpCOHb}$, and one as a back up), which probably reflects what would happen in clinical practice, but the bias and error values we found reflect the characteristics of those 3 RAD-57s and might not be generalizable to all instruments. The comparison instrument (RapidPoint 405) was evaluated on each measurement day, with
3 levels of blood gas controls, that included oximetry. And the RapidPoint 405 performed acceptably on 2 proficiency testing challenges during the data-collection period. Other comparison blood oximeters or $\mathrm{Hb}$ analyzers might produce slightly different results.

\section{Conclusions}

Although our findings suggest that pulse oximetry should not be used in place of invasive measurements, there may be clinical utility in checking $\mathrm{SpHb}$ and $\mathrm{SpCOHb}$ in the context of $\mathrm{D}_{\mathrm{LCO}}$ testing. Noninvasive screening for extreme $\mathrm{Hb}$ or $\mathrm{COHb}$ values may be useful to guide whether a blood sample is needed. For patients who have abnormal screening results, an invasive measurement can be performed to allow appropriate adjustments for interpretive purposes. Clinically important differences in the predicted $\mathrm{D}_{\mathrm{LCO}}$ for most adults require an $\mathrm{Hb} 3-4 \mathrm{~g} / \mathrm{dL}$ higher or lower than normal, or a markedly elevated $\mathrm{COHb}$.

Clinically important differences in the measurement of $\mathrm{Hb}$ and $\mathrm{COHb}$ by the RAD-57 limit its usefulness for adjusting predicted $\mathrm{D}_{\mathrm{LCO}}$ values. However, there may be a role for noninvasive $\mathrm{Hb}$ and $\mathrm{COHb}$ measurement in screening for extreme values that indicate a need for invasive sampling.

\section{REFERENCES}

1. Viegi G, Baldi S, Begliomini E, Ferdeghini EM, Pistelli F. Single breath diffusing capacity for carbon monoxide: effects of adjustment for inspired volume dead space, carbon dioxide, hemoglobin and carboxyhemoglobin. Respiration 1998;65(1):56-62.

2. MacIntyre N, Crapo RC, Viegi G, Johnson DC, van der Grinten CP, Brusasco V, et al. Standardisation of the single-breath determination of carbon monoxide uptake in the lung. Eur Respir J 2005;26(4):720-735.

3. Cotes JE, Chinn DJ, Quanjer PH, Roca J, Yernault JC. Standardization of the measurement of transfer factor (diffusing capacity). Report Working Party Standardization of Lung Function Tests, European Community for Steel and Coal. Official Statement of the European Respiratory Society. Eur Respir J 1993;6:(Suppl. 16):41-52.

4. Gaensler EA, Wright GW. Evaluation of respiratory impairment. Arch Environ Health 1966;12(2):146-189.

5. Altman DG, Bland JM. Measurement in medicine: the analysis of method comparison studies. The Statistician 1983;32:307-317.

6. Bland JM, Altman DG. Statistical methods for assessing agreement between two methods of clinical measurement. Lancet 1986;1(8476): 307-310.

7. Petersen PH, Stöckl D, Blaabjerg O, Pedersen B, Birkemose E, Thienpont L, et al. Graphical interpretation of analytical data from comparison of a field method with a reference method by use of difference plots. Clin Chem 1997;43(11):2039-2046.

8. Jou C, Kurth C, Beckman E, Istaphanous GK. Absolute and trend accuracy of continuous and absolute noninvasive hemoglobin in pediatric surgery patients (abstract). Anesth Analg 2010;110:S401.

9. Lamhaut $\mathrm{L}$, et al. Comparison between a new noninvasive continuous technology of spectrophotometry-based and RBC count for hemoglobin monitoring during surgery with hemorrhagic risk (abstract). Eur J Anaesthes 2010;27(Suppl 47):3AP7-3AP10. 


\section{Multi-Wavelength Pulse Oximeter Is Not Suitable for Adjusting D $_{\text {lco }}$ Measurements}

10. Torp $\mathrm{K}$, et al. Validation of a new non-invasive hemoglobin algorithm in patients undergoing liver transplantation (abstract). Anesthesiology 2009;A751.

11. Chung JW, Park JS, Kim AJ, Shin DW, et al. Non-invasive hemoglobin measurement in emergency patients. J Korean Soc Emerg Med 2010;21(1):67-72.

12. Allard M, et al. Accuracy of noninvasive hemoglobin measurements by pulse co-oximetry in hemodilution subjects (abstract). Anesthesiology 2009;A184.

13. Centers for Disease Control and Prevention. Carbon monoxide-related deaths: United States 1999-2004. MMWR Morb Mortal Wkly Rep 2007;56(50):1309-1312.
14. Piatkowski A, Ulrich D, Grieb G, Pallua N. A new tool for the early diagnosis of carbon monoxide intoxication. Inhal Toxicol 2009; 21(13):1144-1147.

15. Coulange M, Barthelemy A, Hug F, Thierry AL, DeHaro L. Reliability of new pulse CO-oximeter in victims of carbon monoxide poisoning. Undersea Hyperb Med 2008;35(2):107-111.

16. Barker SJ, Curry J, Redford D, Morgan S. Measurement of carboxyhemoglobin and methemoglobin by pulse oximetry; a human volunteer study. Anesthesiology 2006;105(5):892-897.

17. O'Malley GF. Non-invasive carbon monoxide measurement is not accurate (letter). Ann Emerg Med 2006;48(4):477-478.

This article is approved for Continuing Respiratory Care Education credit. For information and to obtain your CRCE

(free to AARC members) visit

www.RCJournal.com 